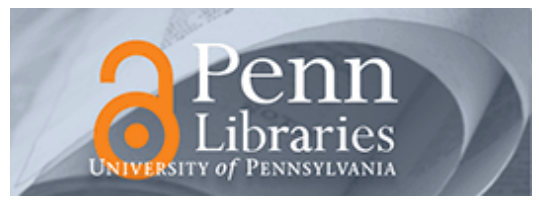

University of Pennsylvania ScholarlyCommons

\title{
Can Nervous Nelly Negotiate? How Anxiety Causes Negotiators to Make Low First Offers, Exit Early, and Earn Less Profit
}

\author{
Alison Wood Brooks \\ University of Pennsylvania \\ Maurice E Schweitzer \\ University of Pennsylvania
}

Follow this and additional works at: https://repository.upenn.edu/oid_papers

Part of the Family, Life Course, and Society Commons, Other Social and Behavioral Sciences Commons, Other Sociology Commons, Policy Design, Analysis, and Evaluation Commons, and the Social Psychology and Interaction Commons

\section{Recommended Citation}

Brooks, A. W., \& Schweitzer, M. (2011). Can Nervous Nelly Negotiate? How Anxiety Causes Negotiators to Make Low First Offers, Exit Early, and Earn Less Profit. Organizational Behavior and Human Decision Processes, 115 (1), 43-54. http://dx.doi.org/10.1016/j.obhdp.2011.01.008 


\title{
Can Nervous Nelly Negotiate? How Anxiety Causes Negotiators to Make Low First Offers, Exit Early, and Earn Less Profit
}

\author{
Abstract \\ Negotiations trigger anxiety. Across four studies, we demonstrate that anxiety is harmful to negotiator \\ performance. In our experiments, we induced either anxiety or neutral feelings and studied behavior in \\ negotiation and continuous shrinking-pie tasks. Compared to negotiators experiencing neutral feelings, \\ negotiators who feel anxious expect lower outcomes, make lower first offers, respond more quickly to \\ offers, exit bargaining situations earlier, and ultimately obtain worse outcomes. The relationship between \\ anxiety and negotiator behavior is moderated by negotiator self-efficacy; high self-efficacy mitigates the \\ harmful effects of anxiety.

\section{Keywords} \\ Anxiety, negotiation, bargaining, emotion, self-efficacy, continuous shrinking-pie game

\section{Disciplines} \\ Family, Life Course, and Society | Other Social and Behavioral Sciences | Other Sociology | Policy Design, \\ Analysis, and Evaluation I Social Psychology and Interaction
}




\section{Can Nervous Nelly Negotiate?
How Anxiety Causes Negotiators to Make Low First Offers, \\ Can Nervous Nelly Negotiate?
How Anxiety Causes Negotiators to Make Low First Offers, Exit Early, and Earn Less Profit}

\author{
Alison Wood Brooks \\ The Wharton School \\ University of Pennsylvania
}

Maurice Schweitzer

The Wharton School

University of Pennsylvania

\section{January 2011}

Russell Ackoff Fellowship of the Wharton Risk Center

Working Paper \# 2011-04

Forthcoming in Organizational Behavior and Human Decision Processes

Risk Management and Decision Processes Center

The Wharton School, University of Pennsylvania

3730 Walnut Street, Jon Huntsman Hall, Suite 500

Philadelphia, PA, 19104

USA

Phone: 215-898-4589

Fax: 215-573-2130

http://opim.wharton.upenn.edu/risk/ 


\section{THE WHARTON RISK MANAGEMENT AND DECISION PROCESSES CENTER}

Established in 1984, the Wharton Risk Management and Decision Processes Center develops and promotes effective corporate and public policies for low-probability events with potentially catastrophic consequences through the integration of risk assessment, and risk perception with risk management strategies. Natural disasters, technological hazards, and national and international security issues (e.g., terrorism risk insurance markets, protection of critical infrastructure, global security) are among the extreme events that are the focus of the Center's research.

The Risk Center's neutrality allows it to undertake large-scale projects in conjunction with other researchers and organizations in the public and private sectors. Building on the disciplines of economics, decision sciences, finance, insurance, marketing and psychology, the Center supports and undertakes field and experimental studies of risk and uncertainty to better understand how individuals and organizations make choices under conditions of risk and uncertainty. Risk Center research also investigates the effectiveness of strategies such as risk communication, information sharing, incentive systems, insurance, regulation and public-private collaborations at a national and international scale. From these findings, the Wharton Risk Center's research team - over 50 faculty, fellows and doctoral students - is able to design new approaches to enable individuals and organizations to make better decisions regarding risk under various regulatory and market conditions.

The Center is also concerned with training leading decision makers. It actively engages multiple viewpoints, including top-level representatives from industry, government, international organizations, interest groups and academics through its research and policy publications, and through sponsored seminars, roundtables and forums.

More information is available at http://opim.wharton.upenn.edu/risk. 
Running Head: ANXIOUS NEGOTIATOR

Can Nervous Nelly Negotiate?

How Anxiety Causes Negotiators to Make Low First Offers, Exit Early, and Earn Less Profit

ALISON WOOD BROOKS

532.4 JMHH, 3730 Walnut Street

The Wharton School

University of Pennsylvania

Philadelphia, PA 19104-6340

Tel: 215-573-0506

Email: awood@wharton.upenn.edu

MAURICE E. SCHWEITZER

566 JMHH, 3730 Walnut Street

The Wharton School

University of Pennsylvania

Philadelphia, PA 19104-6340

Tel: 215-898-4776

Email: schweitzer@wharton.upenn.edu

Forthcoming in Organizational Behavior and Human Decision Processes Accepted January 27, 2011 


\section{Acknowledgements}

The authors thank Deborah Small, Adam Grant, Katherine Klein, Howard Kunreuther, Wendy Ham, Jihae Shin, Shani Ting, and Adam Galinsky for helpful comments. We are grateful for support of the Wharton Behavioral Lab and the Wharton Risk Management and Decision Processes Center. 


\begin{abstract}
Negotiations trigger anxiety. Across four studies, we demonstrate that anxiety is harmful to negotiator performance. In our experiments, we induced either anxiety or neutral feelings and studied behavior in negotiation and continuous shrinking pie tasks. Compared to negotiators experiencing neutral feelings, negotiators who feel anxious expect lower outcomes, make lower first offers, respond more quickly to offers, exit bargaining situations earlier, and ultimately obtain worse outcomes. The relationship between anxiety and negotiator behavior is moderated by negotiator self-efficacy; high self-efficacy mitigates the harmful effects of anxiety.
\end{abstract}

Keywords: anxiety; negotiation; bargaining; emotion; self-efficacy; continuous shrinking pie game 
Can Nervous Nelly Negotiate? How Anxiety Causes Negotiators to Make Low First Offers, Exit Early, and Earn Less Profit

In almost every social and organizational setting, people face the challenge of negotiating with others to achieve their goals (Barry \& Oliver, 1996; Pruitt \& Carnevale, 1993; Rapoport, Budescu, Erev, \& Zwick, 1998). Although a substantial literature has developed our understanding of negotiations (see Bazerman, Curhan, Moore, \& Valley, 2000 for a review), relatively little work has explored how emotions influence negotiator behavior. Important work that has studied emotions in negotiations has focused almost exclusively on anger and happiness (e.g., Allred et al., 1997; Barry, 2008; Van Kleef, De Dreu, \& Manstead, 2004). Surprisingly, prior research has not directly studied one of the most ubiquitous negotiator emotions: anxiety. In this paper, we demonstrate that anxiety is commonly felt before negotiating and harmful to both negotiator behavior and negotiated outcomes.

\section{Moods and Emotions}

Both moods and emotions can influence negotiations. Moods are diffuse feelings characterized by either positive or negative valence (Forgas, 1998). In contrast to moods, emotions are discrete, intense, and complex feelings that last for shorter durations (Smith \& Ellsworth, 1985). Unlike moods that are characterized along a single dimension, valence (good to bad), emotions can be characterized along several dimensions (Smith \& Ellsworth, 1985). For example, anger, sadness, and guilt are all negatively-valenced emotions, but these emotions differ along the dimension of control; anger is typically triggered by another person, sadness is typically triggered by a situation, and guilt is typically triggered by one's own actions. 
In this paper, we study incidental emotion. Incidental emotions are triggered by a prior, unrelated situation (Lerner, Small, \& Loewenstein, 2004). For example, a colleague you meet for lunch may feel angry about a disagreement she had with her spouse earlier in the day. In contrast to incidental emotions, directed emotions are triggered by aspects of the situation itself. Though negotiations are likely to be influenced by both incidental and directed emotions, in our studies, we induce incidental anxiety. Because they are normatively irrelevant (i.e., not related to the task at hand), incidental emotions offer a conservative approach for studying the influence of emotions on judgment and behavior (Dunn \& Schweitzer, 2005).

\section{Affect in Negotiations}

Early work studied the influence of mood on negotiations. This work found that positive moods promote cooperative behavior, and that negative moods promote competitive behavior (Barry \& Oliver, 1996). In particular, positive moods increase concession making, stimulate creative problem solving, and increase preferences for cooperation (Baron, Fortin, Frei, Hauver, \& Shack, 1990; Forgas, 1998). In contrast, negative moods decrease initial offers, decrease joint gains, promote the rejection of ultimatum offers, and increase the use of competitive strategies in negotiations (Forgas, 1998; Pillutla \& Murnighan, 1996).

More recent research has studied the effects of specific emotions on negotiations. This work has identified a number of important relationships between specific emotions and negotiator behavior (e.g., Steinel, Van Kleef, \& Harinck, 2008; Van Beest, Van Kleef, \& Van Dijk, 2008; Van Kleef, De Dreu, \& Manstead, 2004). For example, negotiators concede more to someone who expresses anger than they do to someone who expresses happiness (Van Kleef et al., 2004). Feeling angry, however, can harm negotiators' ability to reach integrative outcomes (Allred et al., 1997). In addition to investigating anger, negotiation scholars have studied 
emotions including envy, disappointment, guilt, and regret (e.g., Van Kleef, De Dreu, \& Manstead, 2006). For example, negotiators who feel envy are more likely to lie to their envied counterpart (Moran \& Schweitzer, 2008). The relationships between specific emotions and negotiator behavior are moderated by a number of factors such as the target of the emotion (e.g., whether the emotion is directed toward a person or a specific behavior) and the number of people negotiating. In extant research, anger and happiness are the most commonly studied emotions in negotiations (Allred et al., 1997; Van Dijk, Van Kleef, Steinel, \& Van Beest, 2008; Van Kleef et al., 2004). Surprisingly, the literature on emotions in negotiations has neglected the study of anxiety. This is an important omission because anxiety may be one of the most pervasive negotiator emotions (Wheeler, 2004).

Anxiety

Although prior work has studied anxiety as a trait, a motive, and a drive (Endler, 1983), we consider anxiety as a state emotion that arises in response to a threat. We integrate prior research on stress and trait anxiety (Gray, 1991; Greenhalgh, 2002; Kantor, Endler, Heslegrave, Kocovski, 2001; O’Connor, Arnold, Maurizio, 2010; Raghunathan \& Pham, 1999; Spielberger, 1966) to introduce the following definition of state anxiety:

Anxiety is a state of distress and/or physiological arousal in reaction to stimuli including novel situations and the potential for undesirable outcomes.

Consistent with prior work (e.g., Gray, 1991), we define anxiety to include fear, frustration, stress, tension, worry, apprehension, and nervousness. Within Russell's (1980) affective circumplex model, anxiety is high in activation and unpleasantness, and within Smith and Ellsworth's (1985) appraisal framework, anxiety is characterized by high uncertainty and a lack of control (Raghunathan \& Pham, 1999). We expect anxiety to be particularly important in 
negotiations. Anxiety differs from other negatively-valenced emotions, such as anger, because it triggers a "flight" rather than a "fight" response (Marks \& Nesse, 1994). For example, whereas feelings of anger motivate individuals to escalate conflict, feelings of anxiety motivate individuals to escape or avoid conflict.

A few scholars have speculated that anxiety may be important for negotiations (Adler, Rosen, \& Silverstein, 1998; Small, Gelfand, Babcock, \& Gettman, 2007; Wheeler, 2004). For example, Babcock, Gelfand, Small, and Stayn (2006) suggest that women may avoid negotiations because they feel anxious. In their studies, women were more likely to avoid negotiations than men, and women were more likely than men to report feeling anxiety and discomfort. Although anxiety may be a prevalent negotiator emotion, no prior work has directly investigated how anxiety influences negotiator behavior.

Anxiety and Flight in Negotiations

Anxiety is triggered by novel situations that have the potential for undesirable outcomes (Gray, 1991). In many negotiations, such as the process of purchasing a home, the situation involves unfamiliar people, unfamiliar issues, and the prospect of unfavorable outcomes (Pruitt \& Carnevale, 1993). For example, an unsuccessful negotiator may upset a counterpart, obtain an adverse outcome, or both. Almost every negotiation is characterized by the potential for undesirable outcomes, and as a result, we expect negotiation settings to trigger anxiety.

Anxiety is an aversive state that motivates individuals to escape or flee from anxietyproducing situations (Marks \& Nesse, 1994). In our investigation, we study the influence of adding incidental anxiety to negotiation and bargaining settings. We expect individuals who feel high levels of anxiety to be eager to escape from anxiety-producing situations, such as negotiation and bargaining situations. 
We consider two ways in which individuals might escape from negotiation and bargaining situations. First, individuals can terminate the process and exit negotiations without reaching a deal. Compared to individuals who experience neutral feelings, we expect individuals who feel anxious to be more likely to exit negotiation and bargaining situations early.

Second, anxious individuals may seek to reach a quick agreement, even when persisting might yield a better economic outcome. To increase the likelihood of reaching a quick agreement, individuals may lower their aspirations, lower their expectations, make low first offers, respond quickly to offers, and make quick concessions. Compared to individuals who experience neutral feelings, we expect individuals who feel anxious to be more likely to lower their aspirations, lower their expectations, make low first offers, and respond more quickly to offers.

We expect anxiety to harm outcomes. Behaviors triggered by anxiety, such as developing low aspirations and expectations (Brophy, 1983), making low first offers (Galinsky, Seidin, Kim, \& Medvec, 2002; Liebert, Smith, Hill, \& Keiffer, 1968; Neale \& Bazerman, 1991; Yukl, 1974), and exiting early (Giebels, De Dreu, \& Van de Vliert, 2000) have each been linked with poor negotiation outcomes. As a result, compared to individuals who experience neutral feelings, we expect individuals who feel anxiety to attain worse negotiation and bargaining outcomes.

In our studies, we also consider self-efficacy, the belief that one can succeed, as a potential moderator of the relationship between anxiety and bargaining behavior. Individuals with high self-efficacy persist in tasks longer than do individuals with moderate or low selfefficacy (Lenta, Browna, \& Larkina, 1984). In our investigation, we expect individuals with high self-efficacy to persist in bargaining tasks longer than those with moderate self-efficacy, even when they feel anxious. 


\section{Pilot Survey}

Although a few scholars have suggested that anxiety is important for negotiations (Adler, Rosen, \& Silverstein, 1998; Wheeler, 2004), extant research has neither documented its importance nor directly studied the influence of anxiety on negotiations. To motivate our investigation, we conducted a pilot study with an adult population.

\section{Method}

Participants. We recruited participants from a large Northeastern train station to complete a one-page survey in exchange for a candy bar. A total of 185 participants (67 female, 84 male) completed the survey. Most respondents had more than three years of work experience (88\%), and on average, participants were 38.6 years old $(S D=16.11)$.

Design and Procedure. The survey contained three sections. In the first section, we asked participants to imagine that they and a stranger were about to negotiate, and to rank the three emotions that they would feel the most before the negotiation. For the ranking task, we gave participants a list of the eight most common emotions from the PANAS basic emotion scale (Happy, Sad, Excited, Guilty, Anxious, Proud, Calm, Angry).

In the second section, we asked participants to imagine "negotiating for a car" and "negotiating for a higher salary." For both of these scenarios, we asked participants to rate the extent to which they would feel each of five emotions using a 5-point scale (Happy, Sad, Anxious, Excited, Angry).

In the third section, we asked participants to provide demographic information (gender and age).

\section{Results and Discussion}


In the first section of the survey, participants ranked the emotions they expected to feel before a generic negotiation. A majority of participants (61.08\%, 113 out of 185) ranked anxiety as the emotion they would feel the most before a negotiation.

In the second section, when participants imagined negotiating over the acquisition of a car, excitement was rated most highly $(M=3.64, S D=1.06)$ and anxiety was rated second-most highly $(M=3.27, S D=1.16)$. In a repeated-measures analysis of variance (ANOVA), we found significant differences between the participants' five emotion ratings, $F(4,158)=149.53, p<$ $.0001, \eta^{2}=.487$. When participants imagined negotiating for a higher salary, anxiety was rated most highly of the five emotions $(M=3.71, S D=1.15)$. In a repeated-measures ANOVA, we found significant differences between the participants' five emotion ratings, $F(4,161)=145.40$, $p<.0001, \eta^{2}=.474$. We depict participants' emotion ratings in Figures 1 and 2.

Insert Figures 1 and 2 about here

Both men and women expected to feel high levels of anxiety. Though we found no significant gender differences, our results are directionally consistent with Babcock et al.'s (2006) conjecture; women anticipated feeling slightly more anxiety than did men (and men anticipated feeling slightly more excitement than did women).

Although prior negotiation work has studied anger and happiness, this work has neglected the study of anxiety. Results from our pilot study reveal that anxiety is commonly felt before negotiating. 
In Study 1, we explore the influence of anxiety on negotiation processes and outcomes. In this study, we induce either anxious or neutral feelings and ask participants to complete a freeform negotiation task based on the cell-phone negotiation case developed by Van Kleef, De Dreu, and Manstead (2004). In this study, participants negotiated with each other via computer instant messaging.

\section{Method}

Participants. One hundred thirty six students at a Northeastern university participated in the study for pay (81 female, 55 male). Participants received a $\$ 10$ show-up fee and had the opportunity to make up to an additional $\$ 15.20$ based on their decisions and the decisions of others in the experiment. On average, participants were 20.1 years old $(S D=1.46)$.

Design. We randomly assigned participants to one of two between-subject conditions: Anxiety vs. Neutral. We induced anxiety or neutral emotions by having participants listen to music via headphones during the negotiation. Prior research has used music to manipulate mood and emotions (e.g., Pham, 1998; see Brown \& Volgsten, 2006 for a review). As a cover story, we informed participants that they would be asked to evaluate the music as part of a separate study.

In the Anxiety condition, we had participants listen to the theme from the movie Psycho. In the neutral condition, we had participants listen to Handel's Water Music: Air. Both of these audio clips are orchestral compositions with no vocal parts. The segments we used were approximately three minutes in length, and we played these clips on a continuous loop.

Pilot Study. We conducted a pilot study to check the effectiveness of our audio clip inductions. We recruited a non-overlapping sample of 162 participants who completed a series of studies in exchange for $\$ 10$. Participants listened to either the anxiety or the neutral clip and rated their emotions while they listened. To measure anxiety, we averaged responses for anxious, 
apprehensive, worried, and nervous $(\alpha=.86)$. To measure neutral feelings, we averaged responses for neutral, indifferent, unemotional, and calm $(\alpha=.91)$.

As expected, mean ratings of anxiety were higher in the Anxiety condition than in the Neutral condition, $t(160)=10.00, p<.001$, and mean neutral feelings were higher in the Neutral condition than they were in the Anxiety condition, $t(160)=6.41, p<.001$. Importantly, ratings of other emotions (e.g., sadness, anger, disgust) did not differ across conditions. We report these results in Table 1.

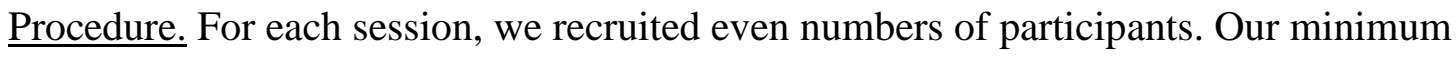
group size was six and the maximum group size was fourteen. After participants arrived, we seated participants in separate cubicles in front of computers with headphones. Participants read all of the instructions and completed the experimental tasks, including the negotiation, via computer.

First, we asked participants to complete an instant messaging practice round to ensure familiarity with the instant messaging platform. Next, participants read background information and prepared for the negotiation task. We then had participants put on headphones. As a cover story, we informed participants that they would be asked to evaluate music as part of a separate study. Participants listened to either the anxiety or the neutral music. While the music played, participants reported their aspiration levels ("What do you hope to earn in the negotiation?") and expectations ("What do you expect to earn in the negotiation?"). After responding to these two questions, participants negotiated with their counterpart.

Participants negotiated via instant message, and we recorded the text of their negotiation. After participants negotiated, we collected demographic information and paid participants based on the outcome of their negotiation. 
Negotiation Task. Consistent with prior emotion and negotiation research, we used a three-issue cell-phone shipment negotiation (De Dreu \& Van Lange, 1995; Van Kleef et al., 2004). We informed participants that they would be randomly assigned to the role of either buyer or seller.

Participants negotiated the price, warranty period, and service period of a cell phone shipment with their counterpart. Price was a distributive issue (i.e., win-lose), and warranty period and service period had integrative potential. Participants could expand the size of the total dyadic outcome by trading across these issues. We provided participants with a payoff chart that represented payoffs associated with nine different levels of outcomes for each of the three issues. We depict the Buyer and Seller payoff charts in Table 2. Sellers preferred a high price, short warranty period, and short service period. Buyers preferred a low price, long warranty period, and long service period. The maximum possible individual outcome for both buyers and sellers was $\$ 15.20$. The minimum possible individual outcome was $\$ 0$. The maximum possible joint outcome was $\$ 17.60$. The minimum possible joint outcome was $\$ 12.80$.

We did not provide participants with their counterpart's payoff table, but participants understood that it differed from their own. We told participants that the negotiation could end in one of three ways: they reached a deal, one of the negotiators decided to exit by typing "EXIT," or time ran out before they reached an agreement. We gave participants 10 minutes to negotiate. If they reached an agreement, we told them they would earn the negotiated amount. If one of the counterparts exited before the end of the 10 minutes, we told them that both counterparts would earn $\$ 4$. And if they did not reach an agreement before the end of 10 minutes, we told them that both negotiators would earn $\$ 0$. Participants completed the negotiation task over an instant messaging platform using an anonymous screenname (e.g., NegotiatorA, NegotiatorB). 
Results

We report results for both the negotiation process and negotiated outcomes. Across our analyses, we found no significant differences for age or gender, and we report results collapsed across these variables.

$\underline{\text { Aspirations and Expectations. We conducted an analysis of variance (ANOVA) on }}$ aspiration level as a function of emotion condition (Anxiety v. Neutral) and role (Buyer v. Seller). We did not find a significant effect of emotion on aspiration level $(p=.60)$. Anxious participants $(M=\$ 11.55, S D=3.60)$ aspired to earn as much as non-anxious participants did $(M$ $=\$ 11.93, S D=3.50)$. We also did not find an effect of negotiator role on aspiration level $(p=$ $.57)$.

We conducted an ANOVA on expectations as a function of emotion condition (Anxiety v. Neutral) and role (Buyer v. Seller). We found a significant effect of emotion on expectations. Controlling for role, anxious participants expected to earn less $(M=\$ 6.95, S D=2.57)$ than did non-anxious participants $(M=\$ 8.31, S D=2.97), F(1,139)=8.46, p=.004$. We found no effect of negotiator role on expectations $(p=.79)$.

First Offers. Sixty five of the 136 participants made complete first offers that specified values for all three issues. About half (31 of 65) of the first offers were made by sellers.

We converted each three-issue initial offer into a total dollar value for the participant who made the offer. We conducted an ANOVA on first offer value as a function of emotion condition (Anxiety v. Neutral) and role (Buyer v. Seller). We found a significant main effect of emotion condition on first offers. Anxious participants made significantly lower first offers $(M=\$ 8.36$, $S D=1.63)$ than did non-anxious participants $(M=\$ 9.55, S D=2.29), F(1,63)=5.63, p=.021$. 
We found no effect of negotiation role on first offer $(p=.93)$. These results are depicted in Figure 3.

Insert Figure 3 about here

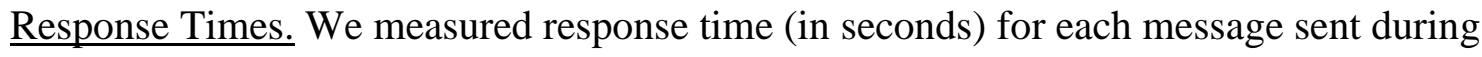
the negotiation. For each participant, we computed averaged response time. We conducted an ANOVA on each participant's mean response time as a function of the negotiator's emotion (Anxious v. Neutral), the counterpart's emotion (Anxious v. Neutral), and the negotiator's role (Buyer v. Seller). We found a significant main effect of the negotiator's emotion on response time. Anxious participants responded significantly more quickly $(M=14.78$ seconds, $S D=5.87)$ than did non-anxious participants $(M=18.42$ seconds, $S D=9.19), F(1,135)=7.32, p=.008$. We did not find a main effect of the counterpart's emotion $(p=.70)$, a main effect of role $(p=.28)$, or interaction effects between the negotiator's emotion, the counterpart's emotion, or role on response time.

Exit Decisions. Only four out of the 142 participants chose to exit before reaching an agreement. Consistent with our predictions, all of the participants who chose to exit were in the anxiety condition, but the total number who exited is too small for us to draw inferences about exit decisions. We investigate exit decisions directly in Studies 3 and 4.

Individual Outcomes. Four dyads failed to reach agreement because one negotiator chose to exit. We excluded these eight participants from our analysis of negotiation outcomes. For each of the 134 participants who reached a deal, we computed the total profit they earned. 
We conducted an ANOVA on individual profit as a function of the negotiator's emotion, the counterpart's emotion, and the negotiator's role. We found a significant main effect of the negotiator's emotion on individual profit. Anxious participants earned less profit $(M=\$ 7.19, S D$ $=2.16)$ than did non-anxious participants $(M=\$ 8.04, S D=1.56), F(1,130)=8.53, p=.004$. We also found a significant main effect of the counterpart's emotion on individual profit. Participants who were paired with an anxious counterpart earned significantly more profit $(M=\$ 7.99, S D$ $=1.89)$ than did participants who were paired with a non-anxious counterpart $(M=\$ 7.18, S D$ $=1.92), F(1,129)=6.03, p=.015$. We did not find a significant interaction effect of the negotiator's emotion and the counterpart's emotion $(p=.40)$ or a significant main effect of the negotiator's role $(p=.52)$ on individual outcomes. We report negotiated outcomes by condition and role as well as the number of dyads per experimental condition in Table 3.

Expectations as Mediator. Following Baron and Kenny's (1986) four-step mediation approach, we analyzed expectations as a mediator of the relationship between anxiety and individual profit. We regressed emotion condition on individual profit. Anxiety was a significant predictor of individual profit $(\beta=-.903, \mathrm{SE}=.314 p<.005)$. We then regressed emotion condition and expectations on individual profit. By including expectations in the model, the influence of anxiety on individual profit was reduced in significance (from $\beta=-.903, p=.0047$ to $\beta=-.729$, $p=.024)$, and we increased the amount of explained variance from $r^{2}=.059$ to $r^{2}=.093$. This suggests that expectations partially mediate the relationship between anxiety and individual profit.

Dyadic Outcomes. We conducted an ANOVA on the total profit dyads earned as a function of the buyer's emotion condition, the seller's emotion condition, and an interaction between the two. We did not find significant effects for the buyer's emotion condition $(p=.78)$, 
the seller's emotion condition $(p=.75)$, or the interaction between the two $(p=.21)$ on dyadic profit.

\section{Discussion}

Study 1 demonstrates that anxiety harms negotiation processes and outcomes. In this study, anxious negotiators set lower expectations, made lower first offers, responded more quickly to offers, and attained worse individual outcomes. Though anxiety caused negotiators to lower their expectations, anxiety did not cause negotiators to lower their aspirations. This pattern of results suggests that anxiety temporarily lowers negotiators' self-efficacy, the belief that one can succeed in a negotiation (i.e, short-term expectations), but does not influence long-term goals (i.e., aspirations). Importantly, Study 1 lacked experimental control over some of our process measures. For example, we did not control the amount of discussion participants had before they made their first offers.

\section{Study 2}

In Study 2, we extend our investigation to explore the link between anxiety and initial offers. The first offer is a critical element of negotiations because it anchors the negotiation. In our setting, negotiators had a complete payoff matrix that bounded the negotiation space. As a result, in our setting, the first offer represents the first opportunity for negotiators to make concessions. Previous work has linked first offers with subsequent patterns of concessions and, ultimately, negotiated outcomes (Galinsky, Seidin, Kim, \& Medvec, 2002; Liebert, Smith, Hill, \& Keiffer, 1968; Neale \& Bazerman, 1991; Yukl, 1974).

Unlike Study 1, we use a very controlled computer-mediated negotiation procedure. We adapted this approach from Van Kleef, De Dreu and Manstead (2004). Though this study lacks the interpersonal interaction of Study 1, it affords us greater control over issues such as the 
amount of information exchanged and self-selection issues that might influence first offers. We also extend our investigation in Study 2 by using a different emotion induction.

Method

Participants. We recruited 159 students at a Northeastern university to participate in a laboratory experiment for pay (72 female, 87 male). Participants received a $\$ 10$ show-up fee and had the opportunity to make up to an additional $\$ 5$ based upon their decisions in the experiment. On average, participants were 19.8 years old $(S D=2.42)$.

Design. We randomly assigned participants to one of two between-subject emotioninduction conditions (Anxiety vs. Neutral). We induced emotions by showing participants one of two film clips. Participants in the anxiety condition viewed a clip from the movie Vertical Limit (Frederickson \& Branigan, 2005). In this video clip, a family climbs the face of a cliff and some of the climbers plummet to their death. Participants in the neutral condition viewed a clip from Planet Earth. This video shows fish swimming in an ocean, accompanied by calm, descriptive narration.

Pilot Study. We conducted a manipulation check of our video clip induction with a nonoverlapping sample of 64 participants who completed a series of studies in exchange for \$10. These participants watched one of the two video clips (Anxiety vs. Neutral) and rated their emotions after watching the video. To measure anxiety, we averaged responses for anxious, apprehensive, worried, and nervous $(\alpha=.84)$. To measure neutral feelings, we averaged responses for neutral, indifferent, unemotional, and calm $(\alpha=.95)$.

After our manipulation, feelings of anxiety were significantly higher in the anxiety condition than in the neutral condition, $t(62)=7.48, p<.001$, and neutral feelings were higher in the neutral condition than in the anxiety condition, $t(62)=5.80, p<.001$. Importantly, other 
negatively-valenced emotions (e.g., sadness, anger, and disgust) did not significantly differ across conditions.

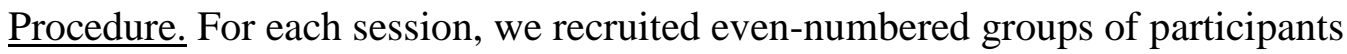
(minimum group size was six participants) to the laboratory. We seated participants in separate cubicles in front of computers with headphones. We presented all of the instructions and experimental tasks on the computer screen. We told participants that they would complete a computer-mediated negotiation with another participant (whose behavior was in fact simulated by the computer). We tested their understanding of the negotiation with a comprehension check. Participants who failed the comprehension check twice were dismissed from the study $(n=8)$.

After completing the comprehension check, participants watched the video clip. We explained this task to participants as a separate study about memory. After watching the video, participants made their first offer in the negotiation.

Negotiation Task. Consistent with Study 1 and previous work, we used a three-issue cellphone shipment negotiation (De Dreu \& Van Lange, 1995; Van Kleef et al., 2004). However, unlike Study 1, in Study 2 the counterpart was simulated by a pre-programmed set of computer responses. We informed participants that they would be assigned to either the role of buyer or seller. After a brief pause during which the computer purportedly assigned roles to each participant, we assigned every participant to the role of seller.

We did not provide participants with the buyer's payoff table, but participants understood that it differed from their own. We told participants that only those who reached an agreement would earn additional money. We told participants that the seller would make the first offer, the buyer would see the offer and make a counteroffer, and the negotiation would continue until they reached an agreement or until time ran out. We explained that there would be at least six rounds 
of offers and counteroffers, but that they would not know the exact length of the negotiation. In fact, every negotiation ended after the sixth round of offers (as in Van Kleef et al., 2004). After the instructions and a comprehension check, sellers made their first offer.

First offers capture negotiator behavior immediately following the emotion induction. We postulate (and demonstrate in Study 3) that the effects of our movie clip induction dissipate quickly. In this study, participants knew the full range of possible offers. Therefore, we conceptualize first offers as a form of concessionary behavior.

\section{Results and Discussion}

Supporting our prediction, participants in the anxiety condition made significantly lower first offers $(M=\$ 11.77, S D=2.55)$ than did participants in the neutral condition $(M=\$ 12.73, S D$ $=2.20), t(147)=2.45, p=.015$. This result is depicted in Figure 4. We did not find significant differences across conditions in subsequent rounds of the negotiation.

\section{Insert Figure 4 about here}

Participants in the anxiety condition made steeper initial concessions (i.e., lower first offers) than did participants in the neutral condition. This finding supports our prediction, and suggests that anxious negotiators are more eager than non-anxious negotiators to escape negotiations. We test this hypothesis directly in Study 3.

\section{Study 3}

In Study 3, we shift our focus from negotiation to bargaining situations. Bargaining situations are abstracted versions of negotiations, and behavior in bargaining situations enables scholars to study behaviors that have important implications for both bargaining and 
negotiations. In this study, we examine the influence of anxiety on deliberate exit decisions in a bargaining game. Consistent with our thesis, we expect anxious individuals to exit bargaining situations earlier than individuals who are not anxious.

We study exit decisions in a modified version of the shrinking pie game. A substantial literature has studied bargaining behavior with shrinking pie games (e.g., Rubinstein, 1982; Weg, Rapoport \& Felsenthal, 1990), including the shortest version of the shrinking pie game, the ultimatum game (e.g., Bolton \& Zwick, 1995; Solnick \& Schweitzer, 1999). In this study, we introduce a new variation of the shrinking pie game to study exit decisions in a bargaining context.

Method

Participants. One hundred seventy-nine students at a Northeastern university participated in the study for a $\$ 10$ show-up fee and the opportunity to make up to an additional $\$ 23$ based upon their decisions and the decisions of others in the experiment (92 female, 87 male). On average, participants were 20.1 years old $(S D=1.89)$.

Design/Procedure. In this study, there were two within-subjects conditions (Anxiety v. Neutral). Participants read instructions, completed a comprehension check, watched the first video clip, completed the first bargaining task, watched a second video clip, and then completed a second bargaining task with a new partner. The order in which the video clips were presented was counterbalanced between subjects.

Bargaining Task. We developed a continuous version of the shrinking pie game (Rubinstein, 1982; Weg, Rapoport \& Felsenthal, 1990). The original version of the shrinking pie game involves two players who make sequential moves to decide how to divide a "pie" or sum of money. In the first round, the first player proposes a division of the pie. The second player can 
either accept or reject this proposed split. If the second player rejects the proposed division, the pie shrinks, and the second player proposes a division of the reduced pie. The first player can then either accept or reject the new proposal. If the first player rejects the proposed division, the pie shrinks again, and the first player proposes another division of the reduced pie. This procedure continues until one of the parties accepts a proposed division or the game ends with an imposed payoff (e.g., \$0, \$0). This bargaining game has been called the "shrinking pie" game because the size of the sum of money shrinks at each stage of the game (Rubinstein, 1982).

The shrinking-pie game is very similar to the ultimatum game, which has been extensively studied to investigate bargaining behavior. In fact, the one-round version of the shrinking-pie game is equivalent to the ultimatum game. In the ultimatum game, the first player proposes a division of the pie, the second player either accepts or rejects the proposed division, and the game ends. Studies involving the ultimatum game have examined a number of negotiation-relevant topics, including fairness, deception, emotion, and even physical attractiveness (Blount \& Larrick, 2000; Fehr \& Schmidt, 1999; Moran \& Schweitzer, 2008; Solnick \& Schweitzer, 1999).

Like the ultimatum game, the shrinking-pie game measures an important aspect of bargaining and negotiation behavior: the decision to exit. The shrinking pie game is particularly well-suited for our investigation because it involves a relatively short interaction that follows an emotion induction. In this study, we used a movie-clip induction that may dissipate before the end of a lengthy or involved negotiation.

We develop a modified version of the shrinking-pie game. In our version, two players make simultaneous decisions to stay or to exit the bargaining game as the pie shrinks continuously over time. In our experiment, the pie starts at $\$ 30$ and decreases by fifty cents every 
second (until the pie equals $\$ 0$ after 60 seconds). Participants can stop the clock by choosing to exit any time during the 60 seconds.

The first player to exit stops the clock and determines the size of the pie. The first player to exit earns $25 \%$ of the pie and the second player to exit earns $75 \%$ of the pie. In this game, players choose exit decisions to balance two competing concerns; early exit ensures a large pie size, but increases the likelihood of claiming a small share of the pie.

In this experiment, participants learned that they would be matched with another participant in the session to complete a computer-mediated bargaining task. We presented each participant with the payoff information depicted in Figure 5, an animation of how the pie decreases over time. We informed participants that their counterpart would see the same figure. We also told participants that if both participants waited until the end to exit, they would both earn $\$ 0$.

We informed participants that they would make their decisions simultaneously and independently; participants would not know when their counterpart decided to exit until after they had made their own decision. We also informed participants that they would make two rounds of decisions with a different counterpart each time. Finally, we informed participants that we would pay them based on one randomly selected round's outcome.

Insert Figure 5 about here

\section{Results and Discussion}

Supporting our prediction, participants in the Anxiety condition exited the bargaining situation earlier $(M=19.20$ seconds, $S D=15.17)$ than did participants in the Neutral condition $(M=24.79$ seconds, $S D=17.60)$. In a one-way repeated-measures analysis of variance 
(ANOVA) within subjects, we found that this relationship was significant, $F(1,177)=38.21, p$ $<.0001$. We depict this effect in Figure 6. We found no order effects for the sequence in which we presented the video clips (anxiety clip first v. neutral clip first).

Insert Figure 6 about here

Results from Study 3 demonstrate that anxiety causes individuals to exit early. We believe that the decision to exit in this bargaining context is indicative of exit tendencies more broadly.

Study 4

In Study 4, we consider an important moderator of the influence of anxiety on exit behavior. Prior research has found that people tend to believe that they are below average in performing difficult skill-based tasks, such as negotiating (Moore \& Cain, 2007). Other work, however, has found that negotiators with high self-efficacy may feel confident in their negotiating ability and insulate themselves from the prospect of negative outcomes. Negotiator self-efficacy is the belief in one's ability to perform well in a negotiation (Bandura, 1993; Sullivan, O’Connor, \& Burris, 2006).

We postulate that individuals with high negotiator self-efficacy are less affected by anxiety than are negotiators with average negotiator self-efficacy. Specifically, we expect negotiators with high self-efficacy to persist in difficult negotiations, and we predict that anxiety influences negotiators with high self-efficacy less than it influences negotiators with moderate self-efficacy. In Study 4, we consider the role of negotiator self-efficacy in moderating the relationship between anxiety and early exit. 
Method

Participants. One hundred fifty-nine students at a Northeastern university participated in the study for a $\$ 10$ show-up fee and the opportunity to earn up to an additional $\$ 23$. On average, participants were 20.3 years old $(S D=2.01)$.

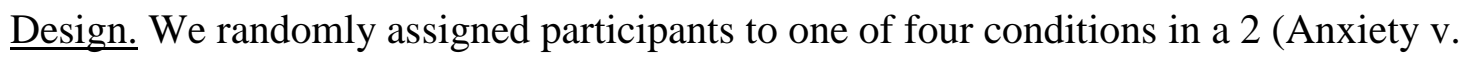
Neutral) x 2 (High self-efficacy v. Average self-efficacy) design. We manipulated emotion (Anxiety v. Neutral) as we did in Studies 2 and 3 with video clips.

We manipulated negotiator self-efficacy by providing false performance feedback (High self-efficacy v. Average self-efficacy) on a "Negotiation Aptitude Test." For this study, we developed the Negotiation Aptitude Test by creating ten questions to purportedly assess negotiation ability. We include the full Negotiation Aptitude Test in the Appendix. We introduced the aptitude test with the following text:

Negotiations often involve balance. For example, some people are too aggressive and some are too passive. Some people focus too much on relationships and some focus too much on their own interests. Though there are often no perfect answers, the Negotiation Aptitude Test (N.A.T.) has been validated on a large U.S. based sample. For example, N.A.T. scores have been linked to a number of real-world outcomes such as starting salaries, home sale prices, and auto purchases.

Following the introduction, participants answered 10 questions, such as the following:

Imagine that you want to purchase a house that has a list price of $\$ 500,000$, but comparable prices for homes range from $\$ 350,000$ to $\$ 450,000$. You can afford to pay $\$ 400,000$. The housing market is rising (house prices are increasing), and there are three other buyers interested in the same house. Of the following options, which is best?

a. Wait for another buyer to make an initial offer.

b. Offer $\$ 400 K$ before the other buyers make offers.

c. Offer $\$ 350 \mathrm{~K}$ before the other buyers make offers.

d. Look for a different house that has fewer interested buyers. 
After participants completed the Negotiation Aptitude Test, we provided them with false performance feedback. In the High self-efficacy condition, we informed participants that they had scored in the $96^{\text {th }}$ percentile. In the Average self-efficacy condition, we informed participants that they had scored in the $47^{\text {th }}$ percentile.

Pilot Study. To assess the effectiveness of the self-efficacy induction, we conducted a manipulation check with a non-overlapping sample of 107 participants who completed the Negotiation Aptitude Test as part of a series of studies they completed in exchange for a $\$ 10$ show-up fee.

We randomly assigned participants to one of two conditions (High self-efficacy v. Average self-efficacy). Participants completed the Negotiation Aptitude Test, received false performance feedback, and then completed a ten-item measure of negotiator self-efficacy (Sullivan, B., O’Connor, K., \& Burris, E., 2005). The ten items included statements such as “I am certain that I can persuade the other negotiator to make most of the concessions" and "I feel confident in my ability to negotiate effectively" (rated on a 5-point scale).

We compared negotiator self-efficacy across conditions. After our manipulation, participants' mean level of negotiator self-efficacy was significantly higher in the High condition $(M=3.60, S D=.53)$ than in the Average condition $(M=3.18, S D=.55), t(105)=4.02, p<.001$.

Procedure. First, participants completed the Negotiation Aptitude Test and received false performance feedback. Second, participants read the instructions for the continuous shrinking-pie bargaining task (as in Study 3) and completed a comprehension check. Next, participants watched one of two emotion-inducing video clips, and then made exit decisions in the continuous shrinking-pie bargaining task.

\section{Results and Discussion}


We found that self-efficacy moderates the influence of anxiety on exit decisions. We conducted a 2 (Anxiety v. Neutral) x 2 (High self-efficacy v. Average self-efficacy) analysis of variance (ANOVA) on exit decisions. We found two significant main effects and a significant interaction. As before, participants in the anxiety condition exited earlier than did participants in the neutral condition, $F(1,155)=4.01, p=.047$. In addition, participants in the low self-efficacy condition exited earlier than did participants in the high self-efficacy condition, $F(1,155)=$ $14.83, p=.0002$. Interestingly, we found a significant interaction between anxiety and selfefficacy, $F(1,155)=4.29, p=.04$. Participants in the Average self-efficacy condition exhibit the same pattern of results we found in Study 3. However, participant in the High self-efficacy condition were not influenced by anxiety. We depict this pattern of results in Figure 7.

Insert Figure 7 about here

General Discussion

For many people, the prospect of negotiating induces anxiety. In fact, anxiety may be the most pervasive negotiator emotion. We demonstrate that anxiety significantly harms negotiator behavior. Compared to negotiators in a neutral emotional state, anxious negotiators lower their expectations, make lower first offers, respond to counteroffers more quickly, and exit negotiations earlier-behaviors that are not explained by other negatively-valenced emotions. In our studies, these behaviors caused anxious negotiators to attain worse outcomes. We also found that negotiator self-efficacy moderates the effects of anxiety on exit behavior. Individuals with high negotiator self-efficacy are less affected by the harmful effects of anxiety.

In our studies, we induced incidental anxiety. This approach afforded us experimental control; every participant experienced the same stimuli, and there were no normative reasons for 
incidental anxiety to influence negotiation behavior. As a result, our studies offer a conservative test of the influence of anxiety on negotiations. In addition to experiencing incidental anxiety, negotiators are likely to experience directed anxiety. The prospect of a difficult negotiation, high stakes, or an abrasive counterpart can trigger anxiety. Future work should investigate different triggers and the effects of directed anxiety on negotiator behavior.

Our findings establish an important link between anxiety and self-efficacy. Future work remains, however, with respect to understanding negotiator self-efficacy itself. Prior research has measured negotiator self-efficacy and linked self-efficacy with tactics and outcomes (Sullivan, O’Connor, \& Burris, 2005), but no prior work has induced negotiator self-efficacy. In this paper, we introduce a tool for inducing negotiator self-efficacy (see Appendix), and we find that negotiator self-efficacy is both labile and consequential. In Study 4, participants who received false performance feedback indicating that they were effective negotiators were more tenacious and made later exit decisions than did negotiators who received false performance feedback indicating that they were average negotiators.

Prescriptively, our findings suggest that negotiators may improve their performance by curtailing their experience of anxiety and by boosting their perceptions of negotiation selfefficacy. For example, negotiation courses as well as negotiation simulations and training more generally may reduce anxiety and improve negotiator performance by boosting negotiator selfefficacy and by making negotiation situations routine (i.e., less novel) and hence less anxiety provoking. Future work should study these relationships and even consider the broader implication that self-affirmation in general may boost generalized self-efficacy and improve negotiation performance. 
Another possible prescription for curtailing the influence of anxiety is to heighten selfawareness of anxiety. Prior work has found that making people aware of their emotional state enables people to correct for the influence of emotions on their judgment (Schwartz, 1990). Perhaps acknowledging feelings of anxiety could serve as a coping mechanism.

Our findings demonstrate that anxiety promotes flight behavior in negotiation. Future work should consider different types of flight. For example, there may be qualitative differences between volitional exit (i.e., deciding to leave prematurely) and an accelerated process (i.e., faster response times). In negotiations, volitional exit may yield impasses, whereas an accelerated process may yield poor agreements. In some cases, incentives may counteract the detrimental effects of anxiety on exit behavior. Quite possibly, even anxious individuals may be persuaded to persist until they reach specific goals, and future work should explore the interplay between incentives and different types of exit. For example, in Study 1, the expected value of exit was much lower than the expected value of reaching an agreement. In this case, few negotiators exited with an impasse. Instead, anxious negotiators accelerated their process by lowering expectations, responding more quickly to counteroffers, and making steeper concessions.

Quite possibly, a strategic negotiator could induce anxiety in a counterpart to extract concessions. Even non-strategic negotiators may induce anxiety in a counterpart, either accidentally or via contagion. Prior work has found that emotions are easily transmitted across individuals (e.g., Barsade, 2002; Hatfield, Cacioppo, Rapson, 1994), and we conjecture that anxiety is highly contagious. Future work should explore issues such as how people perceive anxiety in others and how anxiety spreads between team members and negotiators. 
A number of individual differences may moderate the relationship between anxiety and negotiator behavior. For example, risk attitude impacts negotiator behavior (Bottom, 1998), and differences in risk attitudes may influence the amount of anxiety negotiators experience in uncertain environments. Neuroticism may also matter. Neuroticism is a personality trait associated with the tendency to arouse quickly, to inhibit slowly, and to appraise events as stressful (Costa \& McCrae, 1992). Individuals high in neuroticism may be particularly susceptible to anxiety triggers and the influence of anxiety in negotiation.

We identify an important link between the anxiety individuals experience and negotiation behavior. The association between anxiety and negotiations we measured in our pilot survey, however, was expected anxiety. Though prior work has found that people sometimes mispredict their affective experiences (Robinson \& Clore, 2002), we postulate that the experience of anxiety is a fundamental aspect of many negotiations that merits additional research. For example, future work should study how different aspects of negotiations induce anxiety, how the magnitude of anxiety may change behavior, how anxiety influences information exchange, how anxiety influences negotiator satisfaction, how anxiety influences decisions to enter negotiations, and how anxiety influences patterns of concession.

In addition to describing the importance of anxiety as an anticipatory emotion, our findings highlight the importance of excitement in negotiations. Future work should focus on the influence of excitement in negotiations and explore the interplay between anxiety, excitement, and physiological arousal. Some individuals may conceptualize a negotiation as an anxietyinducing threat, while others may conceptualize the same situation as an exciting challenge. Similarly, though we did not detect significant gender differences in our studies, it is possible 
that men and women may perceive the same opportunities to negotiate quite differently (see Small et al., 2007).

Our findings also relate to the literature on alcohol in negotiations. Many negotiators consume alcohol prior to or during negotiations (Schweitzer \& Kerr, 2000). Alcohol consumption directly influences negotiator behavior (Schweitzer \& Gomberg, 2001), and future work should explore the role of anxiety in both motivating negotiators to consume alcohol as well as alcohol moderating the relationship between anxiety and negotiator behavior.

Finally, although our studies focused on the harmful effects of anxiety, it is possible that mild amounts of anxiety might actually improve negotiator performance. The magnitude of anxiety may have profound effects on behavior. For example, the Yerkes-Dodson Effect suggests a curvilinear relationship between arousal (i.e., stress) and performance. Though very low or very high levels of arousal may be debilitating, a moderate level of arousal may improve performance on difficult tasks like attention, memory, and problem-solving (e.g., Anderson, Revelle, Lynch, 1989; Lupien et al., 2007; Yerkes \& Dodson, 1908). Perhaps moderate amounts of anxiety can increase focus or trigger defensive pessimism (Norem \& Chang, 2002). As a result, some anticipatory anxiety may cause negotiators to prepare more thoroughly. Ultimately, though we identify harmful effects of anxiety for negotiators, mild amounts of anxiety may actually help Nervous Nelly negotiate. 


\section{References}

Adler, R., Rosen, B., \& Silverstein, E. (1998) Emotions in negotiation: How to manage fear and anger. Negotiation Journal, April 1998, 161-179.

Allred, K., Mallozzi, J., Matsui, F., \& Raia, C. (1997). The influence of anger and compassion on negotiation performance. Organizational Behavior and Human Decision Processes, 70, 3, 175-187.

Anderson, K., Revelle, W., Lynch, M. (1989). Caffeine, impulsivity, and memory scanning: A comparison of two explanations for the Yerkes-Dodson Effect, Motivation and Emotion, $13,1-20$.

Babcock, L., Gelfand, M., Small, D., \& Stayn, H. (2006). Gender differences in the propensity to initiate negotiations. In D. De Cremer, M.Zeelenberg, \& J. K. Murnighan (Eds.), Social psychology and economics (pp. 239-262). Mahwah, NJ: Erlbaum.

Bandura, A. (1993). Perceived self-efficacy in cognitive development and functioning. Educational Psychologist, 28, 2, 117-148.

Baron, R., Fortin, S., Frei, R., Hauver, L. \& Shack, M. (1990). Reducing organizational conflict: The role of socially-induced positive affect. International Journal of Conflict Management, 1, 133-152.

Barry, B. (2008). Negotiator affect: The state of the art (and the science). Group Decision and Negotiation, 17, 97-105.

Barry, B. \& Oliver, R. (1996). Affect in dyadic negotiation: A model and propositions. Organizational Behavior and Human Decision Processes, 67, 2, 127-143.

Barsade, S. (2002). The ripple effect: Emotional contagion and its influence on group behavior. Administrative Science Quarterly, 47, 4, 644-675. 
Bazerman, M., Curhan, J., Moore, D., \& Valley, K. (2000) Negotiation. Annual Review of Psychology, 51, 279-314.

Blount, S. \& Larrick, R. (2000). Framing the game: Examining frame choice in bargaining. Organizational Behavior and Human Decision Processes, 81, 43-71.

Bolton, G. \& Zwick, R. (1995). Anonymity versus punishment in ultimatum bargaining. Games and Economic Behavior, 10, 95-121.

Bottom, W. (1998). Negotiator risk: Sources of uncertainty and the impact of reference points on negotiated settlements. Organizational Behavior and Human Decision Process, 76, 89112.

Brophy, J. (1986). Teachers' influences on student achievement. American Psychologist.

Brown, S. \& Volgsten, U. (2006). Music and manipulation: On the social uses and social control of music. Berghahn Books: New York.

Costa, P. \& McCrae, R. (1992). Revised NEO Personality Inventory (NEOPI-R) and Neo FiveFactor Inventory (NEO-FFI). Psychological Assessment Resources, Florida.

De Dreu, C. \& Van Lange, P. (1995) The impact of social value orientation on negotiator behavior and cognition. Personality and Social Psychology Bulletin, 21, 1178-1188.

Deutsch, M. \& Krauss, R. (1962). Studies of interpersonal bargaining, Journal of Conflict Resolution, 6, 52-76.

Dixit, A. \& Nalebuff, B. (1991). Thinking Strategically: The Competitive Edge in Business, Politics, and Everyday Life. W.W. Norton, New York.

Dunn, J. \& Schweitzer, M. (2005). Feeling and believing: The influence of emotion on trust. Journal of Personality and Social Psychology, 88, 736-748. 
Endler, N. (1983). Interactionism: A personality model, but not yet a theory. In M. M. Page (Ed.), Nebraska Symposium on Motivation 1982: Personality - Current theory and research, Lincoln, NE: University of Nebraska Press.

Fehr, E. \& Schmidt, E. (1999). A theory of fairness, competition, and cooperation. Quarterly Journal of Economics, 114, 817-868.

Forgas, J. (1998). On feeling good and getting your way: Mood effects on negotiator cognition and bargaining strategies. Journal of Personality and Social Psychology, 74, 3, 565-577.

Fredrickson, B. L. \& Branigan, C. (2005). Positive emotions broaden the scope of attention and thought-action repertoires. Cognition and Emotion, 19 (3), 313-332.

Galinsky, A., Seiden, V., Kim, P., \& Medvec, V. (2002). The dissatisfaction of having your first offer accepted: The role of counterfactual thinking in negotiations. Personality and Social Psychology Bulletin, 28, 271-283.

Giebels, E., De Dreu, C.K.W., \& Van de Vliert, E. (2000). Interdependence in negotiation: Effects of exit options and social motive on distributive and integrative negotiation. European Journal of Social Psychology, 30, 255-272.

Gray, J. (1991). Fear, panic, and anxiety: What's in a name? Psychological Inquiry, 2, 1, 77-78.

Greenhalgh, L. (2002). Managing anxiety in negotiated decision-making. Working Paper, Dartmouth.

Hatfield, E., Cacioppo, J., \& Rapson, R. (1994). Emotional Contagion. Cambridge, MA: Cambridge University Press.

Kantor, L., Endler, N., Heslegrave, R., \& Kocovski, N. (2001). Validating self-report measures of state and trait anxiety against a physiological measure. Current Psychology, 20, 3, 207-215. 
Lenta, R., Browna, S., \& Larkina, K. (1984). Relation of self-efficacy expectations to academic achievement and persistence, Journal of Counseling Psychology, 31(3), 356-362.

Lerner, J., Small, D., \& Loewenstein, G. (2004). Heart strings and purse strings: Carryover effects of emotions on economic decisions. Psychological Science, 15, 337-341.

Liebert, R., Smith, W. Hill, J., \& Keiffer, M. (1968). The effects of information and magnitude of initial offer on interpersonal negotiation. Journal of Experimental Social Psychology, 4, 431-441.

Lupien, S., Maheu, F., Tu, M., Fiocco, Al, Schramek, T. (2007). The effects of stress and stress hormones on human cognition: Implications for the field of brain and cognition. Brain and Cognition, 65, 209-237.

Marks, I. \& Nesse, R. (1994). "Fear and fitness: An evolutionary analysis of anxiety" in The Maladapted Mind, New York, NY: Elsevier Science Inc., pp. 57-60.

Moore, D. \& Cain, D. (2007). Overconfidence and underconfidence: when and why people underestimate (and overestimate) the competition. Organizational Behavior and Human Decision Processes, 103, 197-213.

Moran, S. \& Schweitzer, M. (2008). When better is worse: Envy and the use of deception. Negotiation and Conflict Management Research, 1, 3-29.

Neale, M. \& Bazerman, M. (1991). Cognition and rationality in negotiation. NewYork: Free Press.

Norem, J. K., \& Chang, E. C. 2002. The positive psychology of negative thinking. Journal of Clinical Psychology, 58: 993-1001.

O’Connor, K., Arnold, J., \& Maurizio, A. (in press). The prospect of negotiating: Stress, cognitive appraisal, and performance. Journal of Experimental Social Psychology. 
Pham, M. (1998). Representativeness, relevance, and the use of feelings in decision making. Journal of Consumer Behavior. 25, 144-159.

Pillutla, M. \& Murnighan, J. (1996). Unfairness, anger, and spite: emotional rejections of ultimatum offers. Organizational Behavior and Human Decision Processes, 68, 208-224.

Pruitt, D. \& Carnevale, P. (1993). Negotiation in Social Conflict. Buckingham, England: Open University Press.

Raghunathan, R. \& Pham, M. (1999). All negative moods are not equal: Motivational influences of anxiety and sadness on decision making. Organizational Behavior and Human Decision Processes, 79, 1, 56-77.

Rapoport, A., Budescu, D., Erev, I., \& Zwick, R. (1998). Games and Human Behavior. Mahwah, NJ, USA: Lawrence Erlbaum Associates, Inc.

Robinson, M. \& Clore, G. (2002) Belief and feeling: Evidence for an accessibility model of emotional self-report. Psychological Bulletin, 128, 934-960.

Rubinstein, A. (1982). Perfect equilibrium in a bargaining model. Econometrica, 50, 97-109.

Russell, J. (1980). A circumplex model of affect. Journal of Personality and Social Psychology, $39,6,1161-1178$.

Schwarz, N. (1990). Feelings as information: Informational and motivational functions of affective states. In E. Higgins \& R. Sorrentino (Eds.), Handbook of motivation and cognition: Foundations of social behavior. New York: Guilford Press.

Schweitzer, M. \& Gomberg, L. (2001). The impact of alcohol on negotiator behavior: Experimental evidence. Journal of Applied Social Psychology, 31(10), 2095-2126. Schweitzer, M., \& Kerr, J. (2000). Bargaining under the influence: The role of alcohol in negotiations. Academy of Management Executive, 14(2), 47-57. 
Small, D., Gelfand, M., Babcock, L., \& Gettman, H. (2007). Who goes to the bargaining table? The influence of gender and framing on the initiation of negotiation. Journal of Personality and Social Psychology, 93(4), 600-613.

Smith, C. \& Ellsworth, P. (1985). Patterns of cognitive appraisal in emotion. Journal of Personality and Social Psychology,48, 4, 813-838.

Solnick, S. \& Schweitzer, M. (1999). The influence of physical attractiveness and gender on ultimatum game decisions. Organizational Behavior and Human Decision Processes, 79, 199-215.

Spielberger, C. (1966). The effects of anxiety on complex learning and academic achievement. In Spielberger (Ed.), Anxiety and Behavior (pp. 361-398). New York: Academic Press.

Steinel, W., Van Kleef, G., \& Harinck, F. (2008). Are you talking to me?! Separating the people from the problem when expressing emotions in negotiations. Journal of Experimental social Psychology, 44, 362-369.

Sullivan, B., O’Connor, K., \& Burris, E. (2005). Negotiator confidence: the impact of selfefficacy on tactics and outcomes. Journal of Experimental Social Psychology, 42, 567581.

Van Beest, Van Kleef, \& Van Dijk, (2008). Get angry, get out: The interpersonal effects of anger communication in multiparty negotiation. Journal of Experimental Social Psychology, 44, 994-1002.

Van Dijk, E., Van Kleef, G., Steinel, W. \& Van Beest, I. (2008). A social functional approach to emotions in bargaining: when communicating anger pays and when it backfires. Journal of Personality and social Psychology, 94, 600-614. 
Van Kleef, G. A., De Dreu, C. K. W., \& Manstead, A. S. R. (2004). The interpersonal effects of anger and happiness in negotiations. Journal of Personality and Social Psychology, 86, $57-76$.

Van Kleef, G., De Dreu, C., \& Manstead, A. (2006). Supplication and appeasement in conflict and negotiation: The interpersonal effects of disappointment, worry, guilt, and regret. Journal of Personality and Social Psychology, 91, 124-142.

Weg, E., Rapoport, A., \& Felsenthal, D. (1990). Two-person bargaining behavior in fixed discounting factors games with infinite horizon, Games and Economic Behavior, 2, 7695.

Wheeler, M. (2004). Anxious moments: Openings in negotiations. Negotiation Journal, April 2004, 153-169.

Yerkes, R. \& Dodson, J. (1908). The relation of strength of stimulus to rapidity of habitformation. Journal of comparative Neurology and Psychology, 18, 459-482.

Yukl, G. (1974). Effects of situational variables and opponent concessions on a bargainer's perception, aspirations, and concessions. Journal of Personality and Social Psychology, 29, 227-236. 


\section{Appendix}

\section{Negotiation Aptitude Test (to manipulate negotiator self-efficacy)}

1. Imagine that you want to purchase a house that has a list price of $\$ 500,000$, but comparable prices for homes range from $\$ 350,000$ to $\$ 450,000$. You can afford to pay $\$ 400,000$. The housing market is rising (house prices are increasing), and there are three other buyers interested in the same house. Of the following options, which is best?
a. Wait for another buyer to make an initial offer.
b. Offer $\$ 400,000$ before the other buyers make offers.
c. Offer $\$ 350,000$ before the other buyers make offers.
d. Look for a different house that has fewer interested buyers.

2. Imagine that you want to buy a house that has a list price of $\$ 200,000$, but comparable prices for homes range from $\$ 150,000$ to $\$ 250,000$. You can afford to pay $\$ 300,000$. The housing market is falling (house prices are decreasing), and there are three other buyers interested in the same house. Of the following options, which is best?

a. Wait for another buyer to make an initial offer.

b. Make a full-price offer of $\$ 200,000$ before the other buyers make offers.

c. Offer $\$ 150,000$ before the other buyers make offers.

d. Look for a different house that has fewer interested buyers.

3. Imagine you have been offered a new job. The company has offered you a salary of $\$ 70,000 /$ year. New hires with similar experience, education, and skills are paid $\$ 75,000 /$ year on average. If you do not take the new job, you will go back on the job market, and the unemployment rate is $10 \%$ (very high). You have no other outside options. Of the following choices, which is best?

a. Tell the company you will only accept the job for $\$ 80,000 /$ year.

b. Tell the company you will only accept the job for $\$ 75,000 /$ year.

c. Accept the offer at $\$ 70,000 /$ year.

d. Reject the offer and go back on the job market.

4. Imagine you have been offered a new job. The company has offered you a salary of $\$ 70,000 /$ year. New hires with similar experience, background, education, and skills are paid $\$ 75,000 /$ year on average. If you do not take the new job, you will go back on the job market, and the unemployment rate is $1 \%$ (very low). You have no other outside options. Of the following choices, which is best?

a. Tell the company you will only accept the job for $\$ 80,000 /$ year.

b. Tell the company you will only accept the job for $\$ 75,000 /$ year.

c. Accept the offer at $\$ 70,000 /$ year.

d. Reject the offer and go back on the job market.

5. Imagine that you are buying a new car. You have found the exact car that you want, and the dealer has it in stock. The list price is $\$ 35,000$, and from your research the dealer invoice is $\$ 28,000$. You really like this car, and you would be willing to pay up to $\$ 35,000$ for it. You 
suspect that other buyers are interested in this same car and that the dealership is not very eager to sell this car. What amount would you make for your first offer?
a. $\$ 28 \mathrm{~K}$
b. $\$ 30 \mathrm{~K}$
c. $\$ 33 \mathrm{~K}$
d. Make the dealership offer the next price.

6. Imagine that you are buying a new car. You have found the exact car that you want, and the dealer has it in stock. The list price is $\$ 35,000$, and from your research the dealer invoice is $\$ 28,000$. You really like this car, and you would be willing to pay up to $\$ 35,000$ for it. You suspect that other buyers are not interested in this same car and that the dealership is very eager to sell this car. What amount would you make for your first offer?
a. $\$ 28 \mathrm{~K}$
b. $\$ 30 \mathrm{~K}$
c. $\$ 33 \mathrm{~K}$
d. Make the dealership offer the next price.

7. Imagine that you are organizing a large party. You are working with a caterer for a sit-down dinner for 200 people. The caterer is charging you $\$ 100$ per person and asks you to commit to the exact number of guests. This caterer is the best in town. You can pay $\$ 20,000$, but you would prefer to pay less. How would you respond to this caterer?

a. Pay full price to ensure good service.

b. Offer the caterer $\$ 80$ per person and commit to 200 people.

c. Offer the caterer $\$ 100$ per person, but insist on paying for only the guests who show up.

d. Shop for alternative caterers to use as competitive leverage.

8. Imagine that you are organizing a large party. You are working with a caterer for a sit-down dinner for 200 people. The caterer is charging you $\$ 100$ per person and asks you to commit to the exact number of guests. This caterer is NOT the best in town. You can pay $\$ 20,000$, but you would prefer to pay less. How would you respond to this caterer?

a. Pay full price to ensure good service.

b. Offer the caterer $\$ 80$ per person and commit to 200 people.

c. Offer the caterer $\$ 100$ per person, but insist on paying for only the guests who show up.

d. Shop for alternative caterers to use as competitive leverage.

9. Imagine you are getting married to the man or woman of your dreams. Your fiancé wants you to sign a prenuptial agreement before you wed because s/he is fairly wealthy. In the case of divorce, the prenuptial offer is to split your wealth and assets $80 \%$ for your spouse, $20 \%$ for you because that is the ratio of your current wealth. What should you do?

a. Agree to sign the prenuptial agreement with the $80 / 20$ division.

b. Agree to sign the prenuptial agreement only with a 50/50 division of wealth and assets to be equitable.

c. Consult with a lawyer and then make a counter-offer. 
d. Refuse to sign the prenuptial agreement because marriage is about love, not material wealth.

10. To what extent are the following statements true?
a. Almost always true
b. Often true
c. Rarely true

-In general, it is better to live with some conflict.

-Not all conflict needs to be managed.

-In reality, most things in life are negotiable.

-Many people are willing to provide the same goods or services for a lower price.

-If you offer someone a low price, they are likely to provide worse service or get insulted.

-When people say that a price is their absolute lowest price, they are telling the truth.

-Once people have their mind set on a certain deal, you cannot change their mind. 
Tables

Table 1.

Mean emotion ratings during music manipulation check (Study 1).

\begin{tabular}{lcccccc}
\hline & & Happy & Sad & Anxious & Neutral & Angry \\
\cline { 3 - 7 } Anxious Music & Mean & 1.94 & 1.18 & 2.17 & 1.85 & 1.27 \\
& SD & $(0.37)$ & $(0.46)$ & $(0.81)$ & $(1.07)$ & $(1.12)$ \\
\cline { 3 - 7 } Neutral Music & Mean & 2.02 & 1.24 & 1.16 & 3.47 & 1.07 \\
& SD & $(0.82)$ & $(0.71)$ & $(0.29)$ & $(1.16)$ & $(0.53)$ \\
\hline
\end{tabular}

Note: Ratings were on a 5-point scale 
Table 2.

Buyer Payoff Chart (Study 1).

\begin{tabular}{lllllll}
\multicolumn{2}{c}{ Price of Phones } & \multicolumn{2}{c}{ Warranty Period } & & \multicolumn{2}{c}{ Service Contract } \\
Price & Payoff & Warranty & Payoff & & Service & Payoff \\
\hline$\$ 150$ & $\$ 0.00$ & 1 month & $\$ 0.00$ & 1 month & $\$ 0.00$ \\
$\$ 145$ & $\$ 1.00$ & 2 months & $\$ 0.60$ & 2 months & $\$ 0.30$ \\
$\$ 140$ & $\$ 2.00$ & 3 months & $\$ 1.20$ & 3 months & $\$ 0.60$ \\
$\$ 135$ & $\$ 3.00$ & 4 months & $\$ 1.80$ & 4 months & $\$ 0.90$ \\
$\$ 130$ & $\$ 4.00$ & 5 months & $\$ 2.40$ & 5 months & $\$ 1.20$ \\
$\$ 125$ & $\$ 5.00$ & 6 months & $\$ 3.00$ & 6 months & $\$ 1.50$ \\
$\$ 120$ & $\$ 6.00$ & 7 months & $\$ 3.60$ & 7 months & $\$ 1.80$ \\
$\$ 115$ & $\$ 7.00$ & 8 months & $\$ 4.20$ & 8 months & $\$ 2.10$ \\
$\$ 110$ & $\$ 8.00$ & 9 months & $\$ 4.80$ & & 9 months & $\$ 2.40$
\end{tabular}

Seller Payoff Chart (Studies 1-4).

\begin{tabular}{llllll}
\multicolumn{2}{c}{ Price of Phones } & \multicolumn{2}{c}{ Warranty Period } & & \multicolumn{2}{c}{ Service Contract } \\
Price & Payoff & Warranty & Payoff & Service & Payoff \\
\hline$\$ 150$ & $\$ 8.00$ & 1 month & $\$ 2.40$ & 1 month & $\$ 4.80$ \\
$\$ 145$ & $\$ 7.00$ & 2 months & $\$ 2.10$ & 2 months & $\$ 4.20$ \\
$\$ 140$ & $\$ 6.00$ & 3 months & $\$ 1.80$ & 3 months & $\$ 3.60$ \\
$\$ 135$ & $\$ 5.00$ & 4 months & $\$ 1.50$ & 4 months & $\$ 3.00$ \\
$\$ 130$ & $\$ 4.00$ & 5 months & $\$ 1.20$ & 5 months & $\$ 2.40$ \\
$\$ 125$ & $\$ 3.00$ & 6 months & $\$ .90$ & 6 months & $\$ 1.80$ \\
$\$ 120$ & $\$ 2.00$ & 7 months & $\$ .60$ & 7 months & $\$ 1.20$ \\
$\$ 115$ & $\$ 1.00$ & 8 months & $\$ .30$ & 8 months & $\$ .60$ \\
$\$ 110$ & $\$ 0.00$ & 9 months & $\$ 0.00$ & 9 months & $\$ 0.00$
\end{tabular}


Table 3.

Mean Negotiated Outcomes (Study 1).

\begin{tabular}{llllll} 
Buyer Emotion & Seller Emotion & Buyer Profit & Seller Profit & Dyadic Profit & $\begin{array}{c}\# \text { of } \\
\text { Dyads }\end{array}$ \\
\hline \multirow{2}{*}{ Anxious } & Anxious & $\$ 7.52(\$ 1.56)$ & $\$ 7.35(\$ 1.88)$ & $\$ 14.87$ & 18 \\
Neutral & Anxious & $\$ 8.18(\$ 1.47)$ & $\$ 6.99(\$ 2.04)$ & $\$ 15.17$ & 14 \\
Anxious & Neutral & $\$ 6.60(\$ 2.09)$ & $\$ 8.38(\$ 2.23)$ & $\$ 14.98$ & 20 \\
Neutral & Neutral & $\$ 7.94(\$ 1.67)$ & $\$ 7.81(\$ 1.06)$ & $\$ 15.75$ & 15 \\
\hline
\end{tabular}

Note: Possible individual profit [\$0, \$15.20]. Possible dyadic profit [\$12.80, \$17.60]. 
Figures

Figure 1. Emotion ratings before negotiating for a higher salary (Pilot Survey)

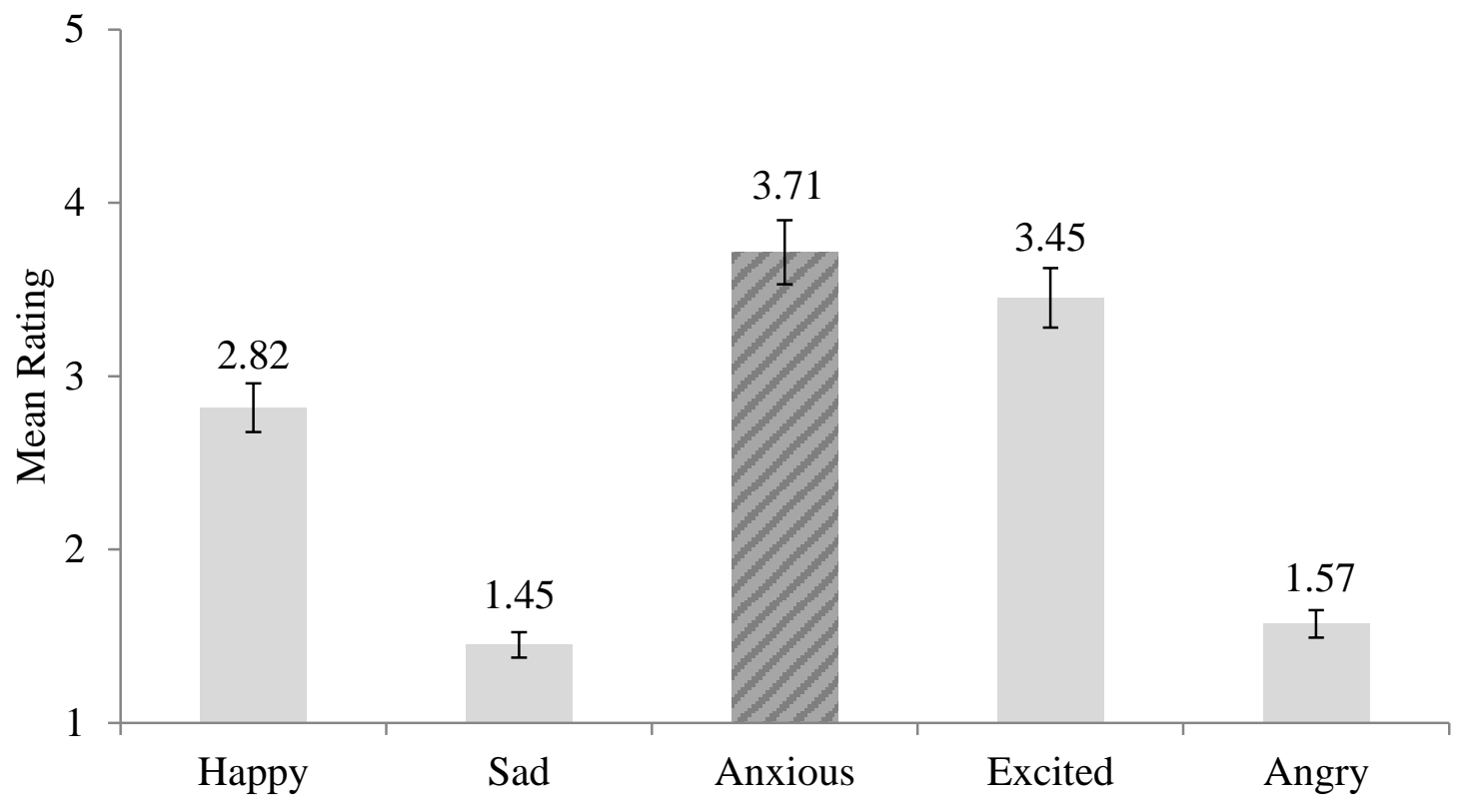


Figure 2. Emotion ratings before negotiating over the price of a car (Pilot Survey)

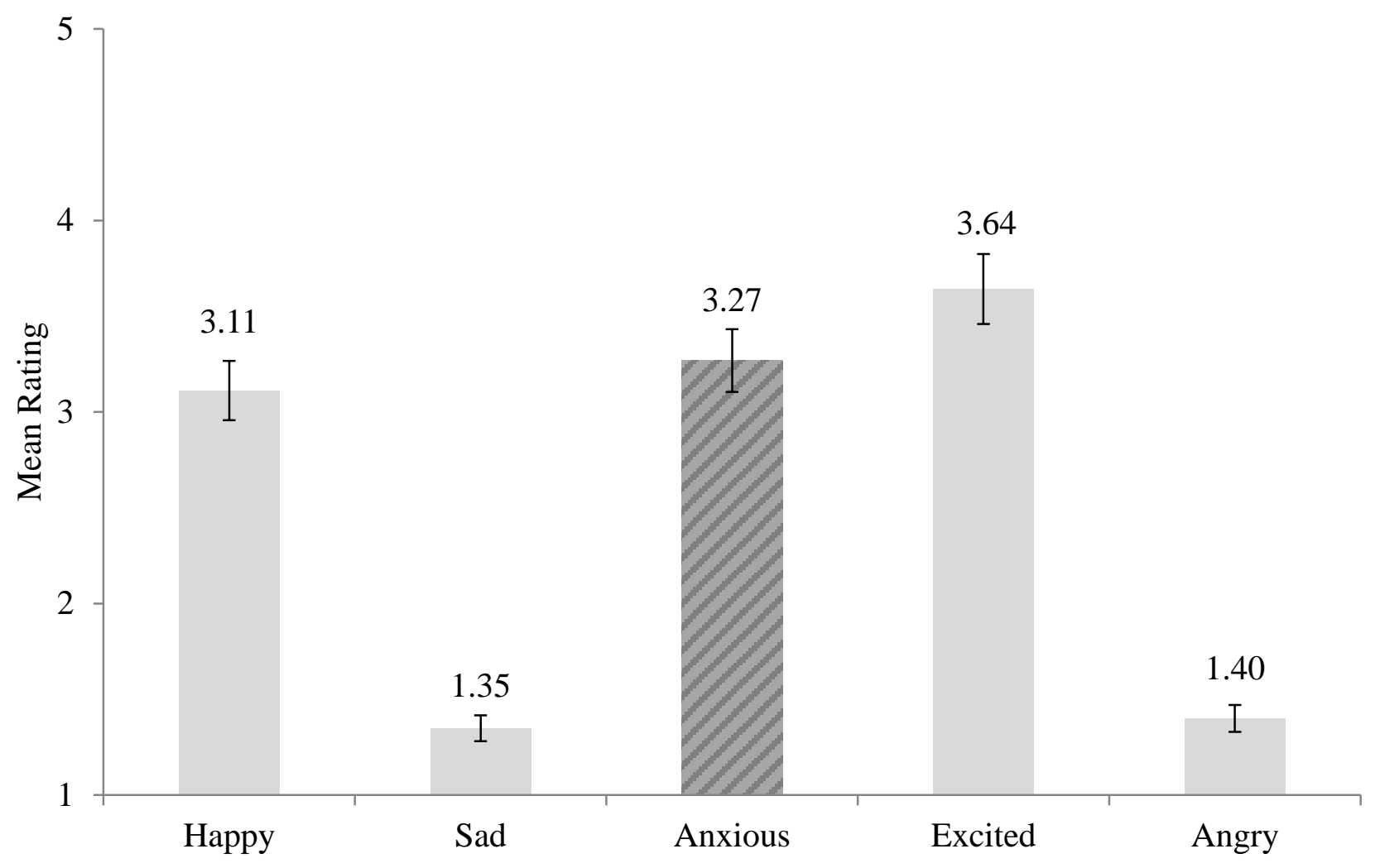


Figure 3. The effect of anxiety on aspirations, expectations, and first offers (Study 1)

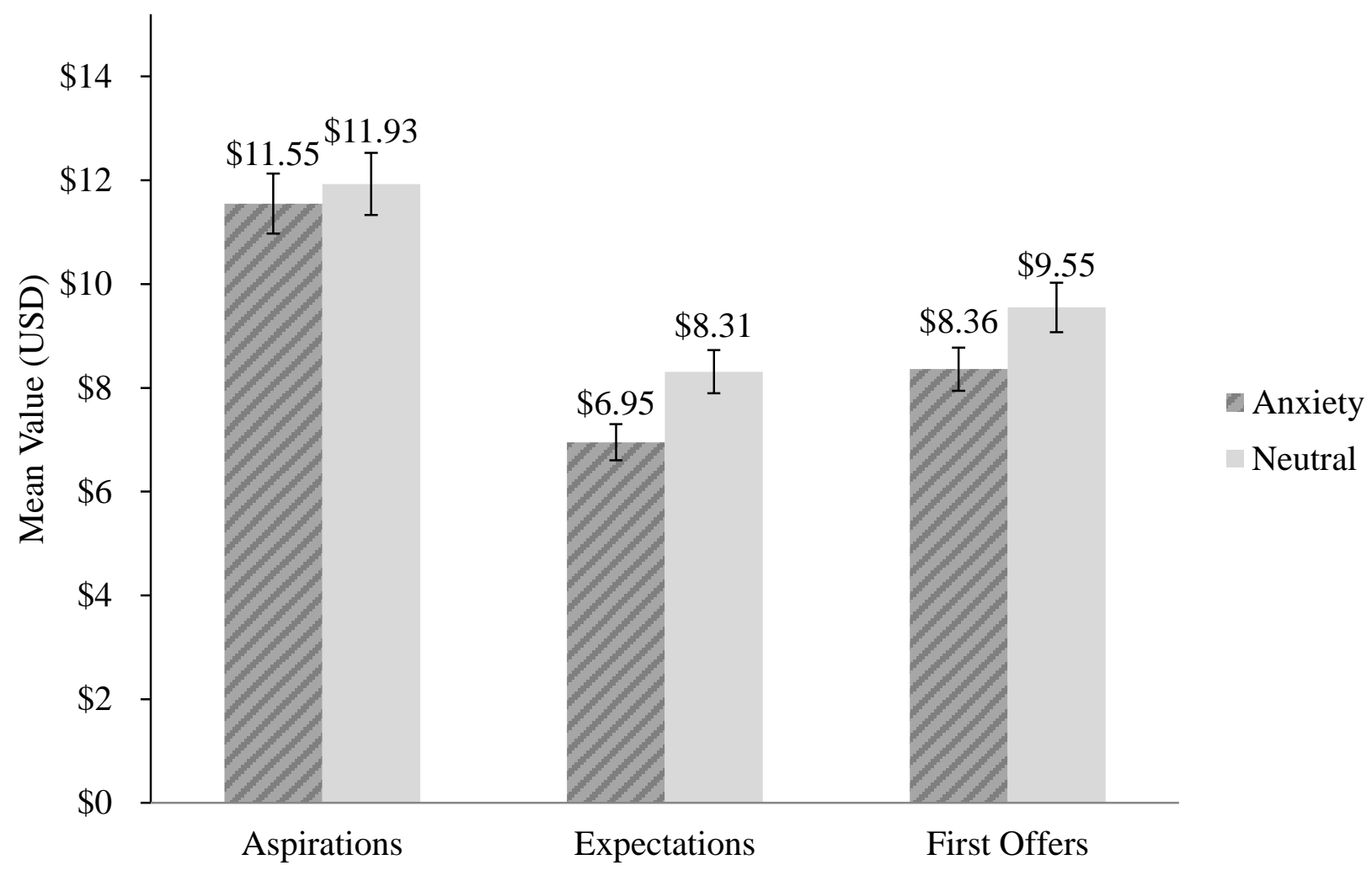


Figure 4. The effect of anxiety on first offers (Study 2)

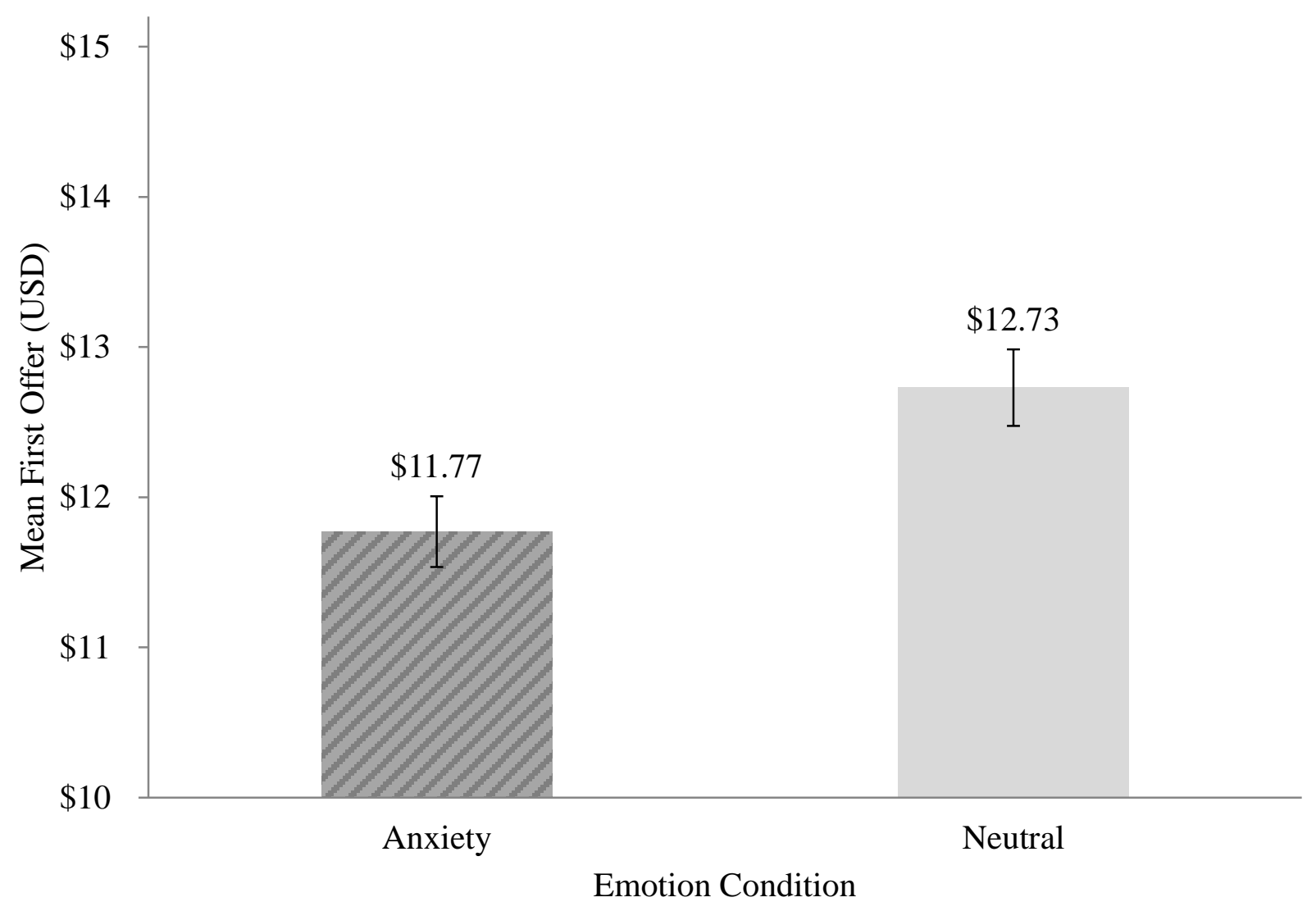


Figure 5. Continuous shrinking-pie bargaining task payoff function (Studies 3-4)

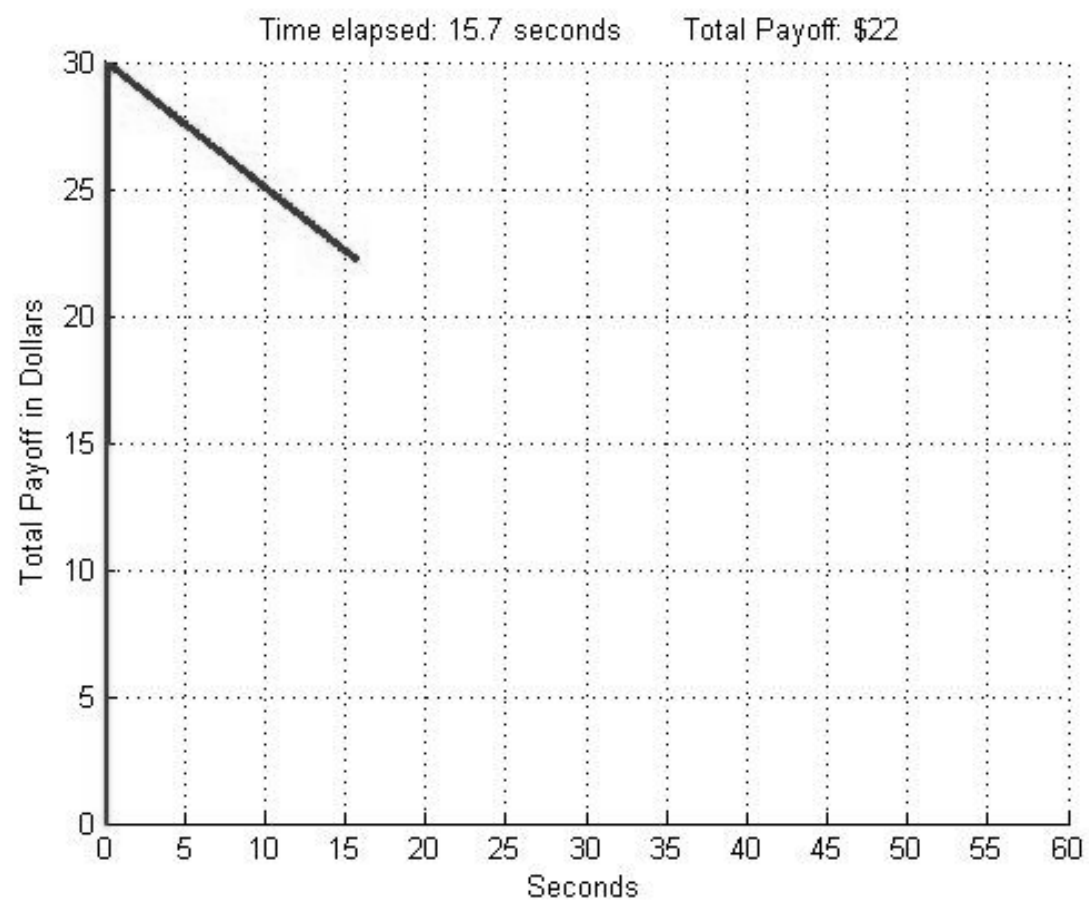

Note: This is a screen-shot of the payoff animation displayed to participants 
Figure 6. The effect of anxiety on exit decisions (Study 3)

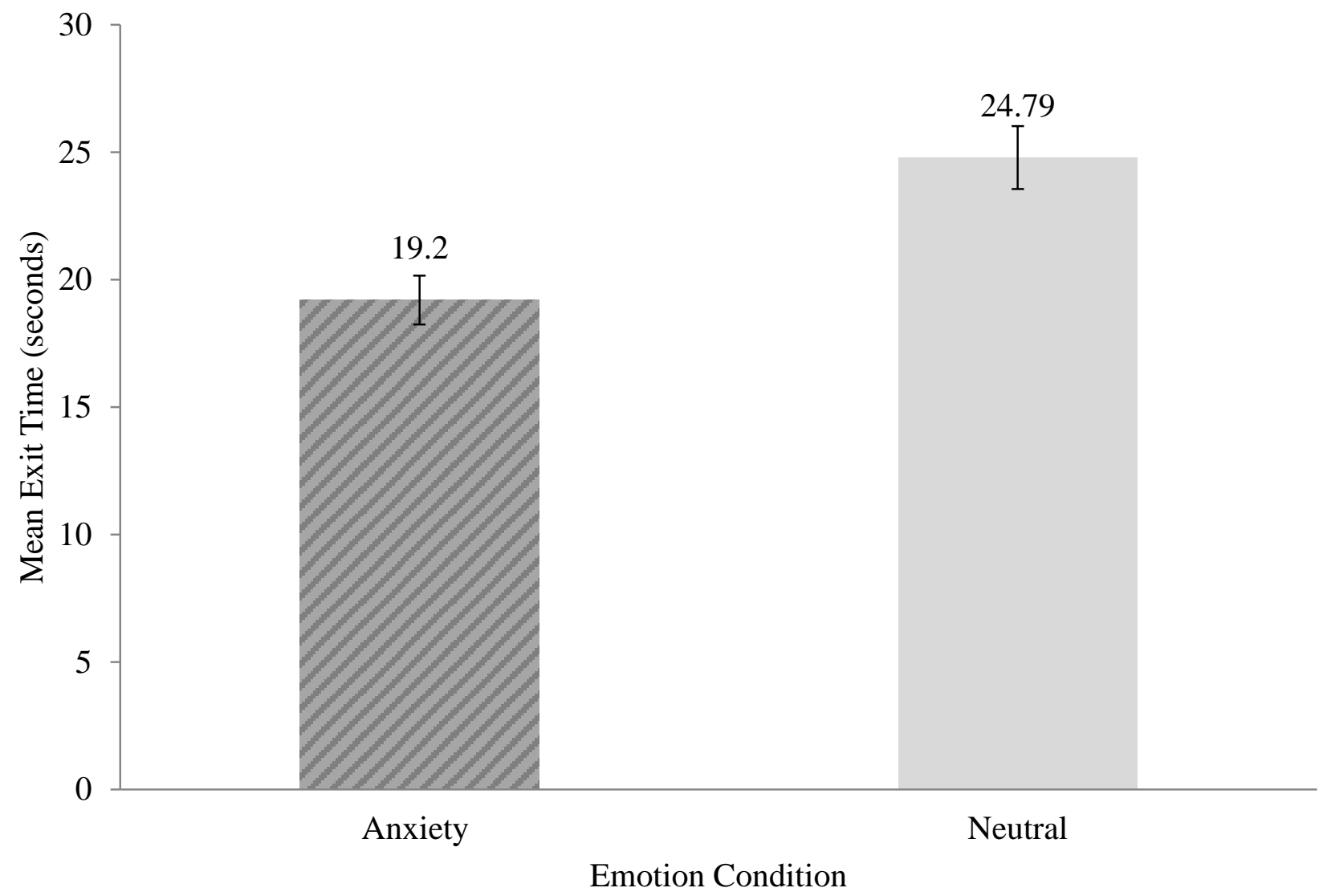


Figure 7. The effects of anxiety and negotiator self-efficacy on exit decisions (Study 4)

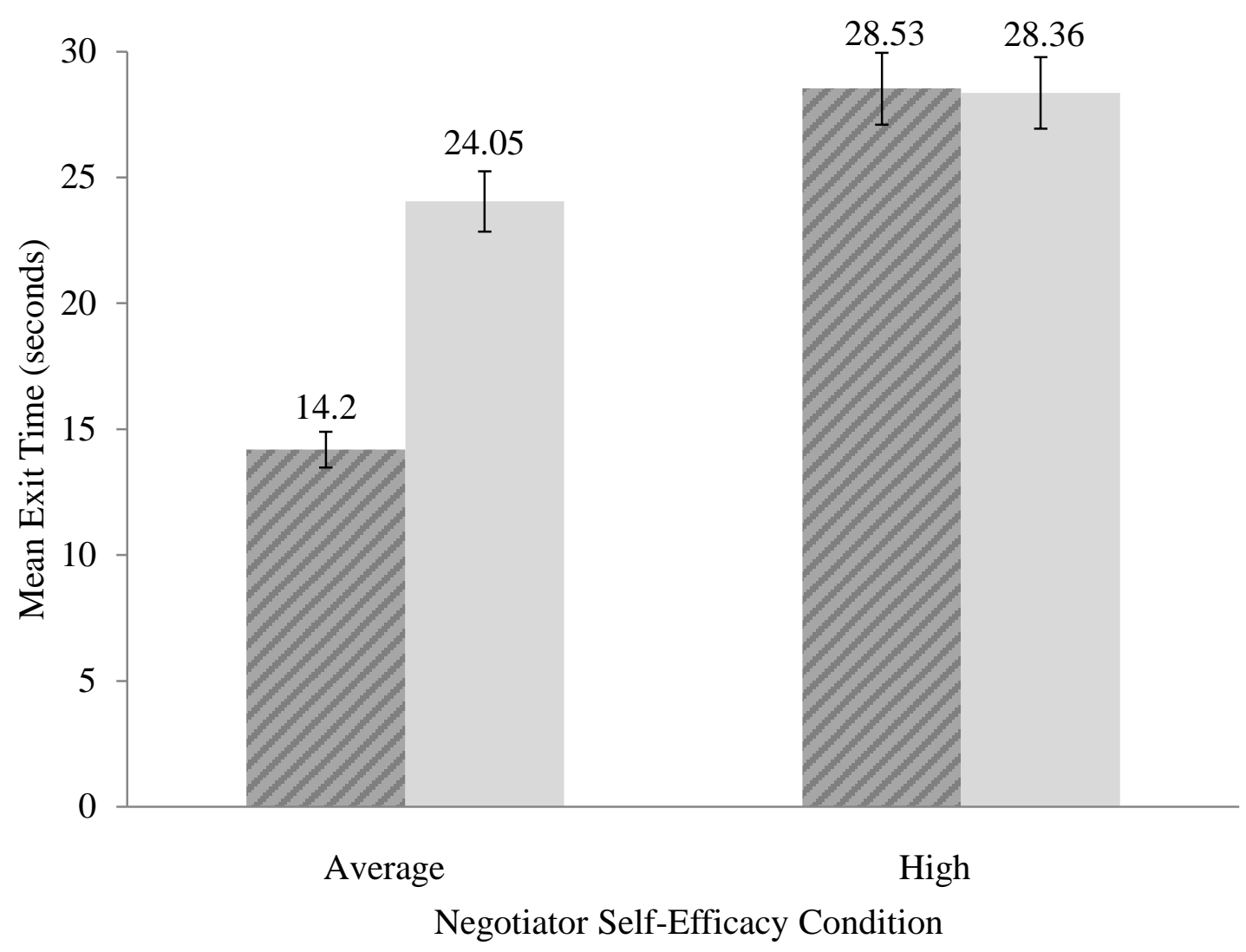

Anxiety

Neutral 